\title{
Isolation and Development*
}

\author{
Quamrul Ashraf \\ Williams College \\ Brown University and CEPR \\ Ömer Özak \\ Brown University
}

September 28, 2009

\begin{abstract}
This paper exploits cross-country variation in the degree of geographical isolation, prior to the advent of sea-faring and airborne transportation technologies, to examine its impact on the course of economic development across the globe. The empirical investigation establishes that prehistoric geographical isolation has generated a persistent beneficial effect on the process of development and contributed to the contemporary variation in the standard of living across countries.

Keywords: Growth, Development, Isolation, Agglomeration, Globalization

JEL Classification: O10, F15, N7
\end{abstract}

*Galor's research is supported by NSF grant SES-0921573. 


\section{Introduction}

Existing theories of comparative development have highlighted a variety of proximate and ultimate factors underlying some of the vast inequities in living standards across the globe. The importance of geographical, cultural and institutional factors, human capital formation, ethnic, linguistic, and religious fractionalization, colonialism and globalization has been at the center of a debate regarding the origins of the differential timing of transitions from stagnation to growth and the remarkable transformation of the world income distribution in the last two centuries. While theoretical and empirical research has typically focused on the contemporaneous effects of such factors or their influence in giving rise to and sustaining the large disparities in income per capita across the globe, attention has recently been drawn towards prehistoric factors that have been argued to affect the course of comparative economic development from the dawn of human civilization to the modern era. ${ }^{1}$

Economic integration and agglomeration have been commonly viewed as beneficial factors in the process of development, reflecting the virtues of technological diffusion and trade. Nevertheless, the diminished ability of geographically isolated societies to benefit from advancements in the world technological frontier, may have induced an independent process of technological advancements, fostering a long-lasting cultural environment conducive to innovations. Moreover, the reduced threat of predation in geographically isolated societies, plausibly enhanced the protection of property rights, fostering the allocation of resources towards investment and innovations, and contributing to the emergence of a persistent cultural atmosphere beneficial for economic development.

While the prevailing conventional wisdom suggests that geographical and thus economic agglomeration have been predominantly virtuous over the course of human history, anecdotal evidence and, in particular, the remarkable performance of China in the midst of self-imposed isolationist policies, suggests that a-priori one cannot reject the hypothesis that some degree of geographical isolation may have been optimal in certain historical periods. Moreover, if indeed geographical isolation fostered a persistent cultural environment that promoted innovations, variation in the degree of geographical isolation in the distant past may have played a significant role in the process of development, thereby contributing to the prevailing variation in economic development across the globe.

This paper exploits cross-country variation in the degree of geographical isolation, prior to the advent of sea-faring and airborne transportation technologies, to examine its impact on the course of economic development through history. It establishes that prehistoric geographical isolation has generated a persistent beneficial effect on the process of development and contributed to contemporary variations in economic development across the globe. In particular, contrary to conventional wisdom, the findings suggest that the degree of prehistoric geographical isolation within the Old World has generated a beneficial effect on economic development in the present as well as in the past, and that this effect

\footnotetext{
${ }^{1}$ In particular, as established by Galor (2010), Unified Growth Theory (Galor and Weil, 2000; Galor and Moav, 2002) implies that variations in deeply-rooted biogeographical factors are critical for understanding the course of comparative economic development throughout human history. Recent evidence (e.g. Diamond, 1997; Olsson and Hibbs, 2005; Putterman, 2008; Ashraf and Galor, 2008a,b) provides support for this hypothesis.
} 
dominates the adverse effect of isolation arising from diminished technological diffusion.

\section{Cross-Country Evidence}

This study investigates empirically the impact of prehistoric geographical isolation on the course of comparative economic development. Specifically, it examines the explanatory power of the cross-country variation in the degree of geographical isolation in the distant past for the global distribution of population density in the years $1 \mathrm{CE}, 1000 \mathrm{CE}$, and $1500 \mathrm{CE}$, and of income per capita in the year $2000 \mathrm{CE}$.

\subsection{The Cross-Country Sample}

The analysis is restricted to the Old World (i.e., Europe, Asia, and Africa) excluding sub-Saharan Africa. This sample is natural in the context of this study for several reasons. First, the Old World (excluding sub-Saharan Africa) is characterized by the early rise of interdependent, advanced civilizations, and thus appears most likely to capture the intensity of the trade-offs associated with the degree of isolation. Second, the broad cross-continental population flows in the post-colonial era and the significant transformations that they have brought to the sociocultural and institutional makeup of the native populations of the New World and sub-Saharan Africa prevent the identification of the effect of the degree of geographical isolation in the distant past within these regions (via the intergenerational transmission of cultural traits in native populations) on their contemporary levels of economic development. $^{2}$ Third, the absence of spatial interactions between societies of the Old and New Worlds since the disappearance of the Bering land bridge (prior to the advent of the Neolithic Revolution) and until the voyage of Columbus in the late 15th century suggests that the inclusion of prehistoric geographical distances between the Old and New Worlds would dilute and obscure the identification of the potential trade-offs associated with isolation, since such trade-offs would clearly not be present in the same scale in hunter-gatherer societies (given their more localized interactions and the inherent glacial pace of their technological advancements).

\subsection{The Index of Isolation}

In order to establish the causal effect of the degree of isolation on economic development, this study develops a novel measure of geographical isolation prevalent in the distant past. The index reflects the average time required to travel from the capital of a country to each square kilometer of land on the surface of the earth, along land routes that minimize travel time in the absence of maritime and airborne transportation technologies. ${ }^{3}$

\footnotetext{
${ }^{2}$ Despite the pattern that countries in sub-Saharan Africa are not only more isolated geographically from the rest of the Old World but have also lagged behind in their economic development, the results uncovered below regarding the beneficial effect of isolation are qualitatively similar for the sample comprising the entire Old World (including sub-Saharan Africa) once the analysis accounts for continental fixed effects and the influence of distances from technological frontiers.

${ }^{3}$ The optimal land routes are computed based on the Human Mobility Index (Ömer Özak, 2009) that reflects the time cost of movement on the surface of the Earth, accounting for natural impediments to
} 
Restricting attention to isolation of countries in relation to all other locations in the entire Old World, the average time required to travel from any other location within the Old World to the capital city of a country within the Old World, excluding sub-Saharan Africa, is 7.5 weeks. This is the level of isolation associated with China. In contrast, traveling to Georgia, the least isolated country in the Old World requires on average 5.5 weeks, while the journey to Malaysia, the most isolated country in the Old World, requires 12.1 weeks.

For any given country, the index of isolation, as mentioned above, is the unweighted average of the time required to reach the country's capital along costminimizing paths. Using an alternative index of isolation that is restricted only to the average time required to travel from the capital of a country to all other capitals does not qualitatively alter the main empirical findings. The employed index, however, is superior as it does not suffer from potential endogeneity arising from the fact that the locational choice involved during the emergence of major urban centers was not orthogonal to the spatial distribution of existing cities.

The index of isolation advanced in this paper therefore permits the exploitation of exogenous variation in the degree of isolation, prior to the advent of sea-faring and airborne transportation technologies, in order to identify the impact of prehistoric geographical isolation on the course of economic development through history.

\subsection{Isolation and Development in the Historical Period}

This section examines the effect of geographical isolation in the distant past on economic development in the pre-colonial era. The examination of comparative development in the pre-colonial era, when societies were in their agricultural stage of development, requires the interpretation of economic outcomes from a Malthusian equilibrium point of view. As established in the cross-country analysis of Ashraf and Galor (2008a), during this era technological advancements and natural land productivity were channeled primarily towards population growth, while income per capita remained stagnant in the long-run. Comparative economic development in this epoch was therefore reflected by population density as opposed to income per capita. In light of this argument, in its first stage, this research examines the effect of prehistoric geographical isolation on population densities in the years $1 \mathrm{CE}$, $1000 \mathrm{CE}$ and $1500 \mathrm{CE}$.

In line with the assertion that prehistoric geographical isolation may have conferred a predominantly beneficial effect on economic development during the pre-colonial era, the regression presented in Column 1 of Table 1 reveals the unconditional positive relationship between the isolation index and log population density in the year 1500 CE. Specifically, the OLS coefficient estimate, which is statistically significant at the $5 \%$ level, implies that a 1 week increase in the average time required to walk to a country's capital from all locations in the Old World is associated with a $25 \%$ increase in its population density in the year $1500 \mathrm{CE}$.

The regression presented in Column 2 separates the gross beneficial effect of isolation from its detrimental effect, arising from the diminished spatial diffusion of technologies. Specifically, it introduces a control for the distance to the closest regional technological frontier (along land routes that minimize travel time). These regional centers of technology diffusion are derived by Ashraf and Galor (2008b) who employ historical urbanization estimates from Chandler (1987) to identify frontiers

human mobility under various topographical and meteorological conditions as reported by Hayes (1996). 
based on the size of urban populations. ${ }^{4}$ In addition, the regression in Column 2 also accounts for potential spillovers that might have occurred from frontiers other than the closest one, by controlling for the average distance to other non-local technological frontiers. Consistently with priors, the beneficial effect of isolation increases in both magnitude and significance once the detrimental effect due to diminished spillovers from technological frontiers is accounted for. Moreover, in line with the diffusion channel, the distance to the closest technological frontier has a significant negative impact on the level of development.

In light of the fact that other geographical factors may have an impact on population density, the regression presented in Column 3 augments the analysis with controls for: (1) the arable percentage of land and proximity to waterways that affects natural land productivity and trade and are thus expected to contribute to population density, (2) absolute latitude that captures the potential effect of variation in climatic conditions on population density, and (3) the number of years elapsed since the occurrence of the Neolithic Revolution, as a proxy for the level of agricultural productivity and technological advancement (Diamond, 1997). Furthermore, to ensure that the effect of isolation on development is not simply a reflection of the scale of surviving isolated economies, the analysis is further augmented with land area as an additional control variable.

Interestingly, the beneficial effect of isolation increases even further in magnitude once the specification is augmented with these additional controls in Column 3. In particular, the increase in the marginal effect of isolation is symptomatic of the fact that the Neolithic transition occurred first in the Fertile Crescent (one of the least isolated regions in the Eurasian landmass) and gradually diffused thereafter to more isolated regions, thereby implying a negative correlation between the degree of geographical isolation and the timing of the Neolithic Revolution. As such, by controlling for the timing of the Neolithic transition, the analysis accounts for an additional detrimental effect of geographical isolation arising from the delay in the diffusion of the new agricultural mode of production. Moreover, in line with the predictions of the Malthusian theory, the timing of the Neolithic transition and the arable percentage of land are both found to have a significant positive effect on population density.

The regression in Column 4 examines the robustness of the results with respect to unobserved continental fixed effects. Reassuringly, the results indicate that the average continent-specific effect of isolation estimated in Column 4 is remarkably similar in magnitude in comparison to the cross-continental effect estimated in Column 3. In particular, the coefficient of interest from Column 4 implies that, conditional on distances to regional technological frontiers, the timing of the Neolithic, land productivity, and continental fixed effects, a 1 week increase in the average time required to travel to a country's capital from all locations in the Old World is associated with a $38 \%$ increase in population density in the year $1500 \mathrm{CE}$. This effect of isolation on population density in the year $1500 \mathrm{CE}$ is depicted on the scatter plot in Figure 1. Finally, Columns 5 and 6 demonstrate that geographical isolation has a similar effect on population density in the years $1000 \mathrm{CE}$ and $1 \mathrm{CE}$ respectively.

\footnotetext{
${ }^{4}$ Specifically, for a given time period, the set of regional frontiers in that period comprises the two largest cities from each continent that belong to different socio-political entities. For $1500 \mathrm{CE}$, the frontiers identified include London (UK), Paris (France), Cairo (Egypt), Fez (Morocco), Constantinople (Turkey), and Peking (China).
} 


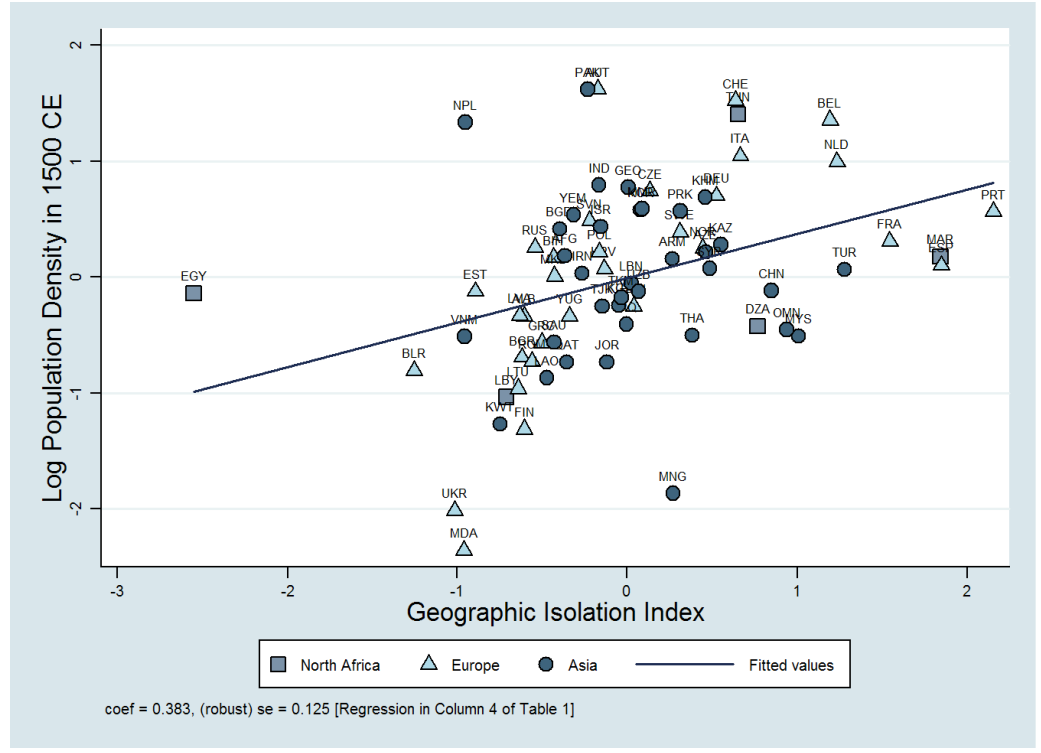

Figure 1: Geographical Isolation and Population Density in $1500 \mathrm{CE}$

Notes - The figure illustrates the partial regression line for the effect of geographical isolation on log population density in the year $1500 \mathrm{CE}$, while controlling for the influence of distance to the regional frontier, the timing of the Neolithic Revolution, the arable percentage of land, absolute latitude, land area, the average distance to non-local frontiers, proximity to waterways, and continent fixed effects. Thus, the $\mathrm{x}$ - and $\mathrm{y}$-axes plot the residuals obtained from regressing isolation and log population density, respectively, on the aforementioned set of covariates.

Thus, consistent with the proposed hypothesis, the analysis establishes that, despite its detrimental effect through the channels of technological diffusion and trade, prehistoric geographical isolation has indeed conferred a persistent beneficial effect on economic development over a prolonged period of time in the pre-colonial era.

\subsection{Isolation and Development in the Contemporary Period}

The effect of isolation in the distant past on contemporary comparative development is examined in Table 2. It presents the results of regressions examining the effect of geographical isolation on income per capita in the year $2000 \mathrm{CE}$. In accordance with the hypothesis that the beneficial effect of geographical isolation on economic development may have persisted to the modern era, Column 1 reveals the unconditional positive relationship between the index of geographical isolation and log income per capita in the year $2000 \mathrm{CE}$. In particular, the estimated regression coefficient, which is statistically significant at the $1 \%$ level, implies that a 1 week increase in the average time required to walk to a country's capital from all locations in the Old World is associated with a $27 \%$ increase in income per capita in the year $2000 \mathrm{CE}$, a correlation that is remarkably similar to that observed between isolation 
and population density in the year $1500 \mathrm{CE} .^{5}$

To disentangle the historically persistent beneficial effect of isolation from its contemporaneous effect (as determined by modern transportation technologies), the regression analysis in Column 2 introduces a control for the average aerial distance from all other capital cities in the world. As one might expect, the persistent beneficial effect of isolation indeed increases in magnitude once the conventional detrimental effect of isolation is controlled for by the analysis. Moreover, consistently with the gravity model, aerial isolation in the contemporary period has a detrimental effect on economic development.

Maintaining symmetry with the historical analysis, Column 3 augments the current investigation with controls for the timing of the Neolithic Revolution and geographical factors gauging the quality and quantity of land. The results indicate that the historically persistent beneficial effect of geographical isolation remains qualitatively robust, maintaining statistical significance and increasing somewhat in magnitude, under these additional controls. Moreover, the long-run persistence of the beneficial effect of the Neolithic Revolution is evident in Column 3, as is the negative association between economic development with the extent to which economies are agriculturally intensive. Finally, as in the historical analysis, the regression specification is further extended to account for unobserved continental fixed effects. As reported in Column 4, the persistent beneficial effect of prehistoric geographical isolation is as prevalent and significant within continents in the modern era as it is across continents.

The robustness of the proposed isolation channel with respect to other determinants of development that have received attention in the literature is assessed in Column 5. Specifically, the analysis introduces controls for (1) the quality of institutions, as captured by the degree of institutionalized constraints on the discretionary power of chief executives, (2) the likelihood of civil conflict and inefficiencies in the provision of public goods, as reflected by the level of ethnic fractionalization, and (3) the disease environment, as revealed by the fraction of the population at risk of contracting malaria.

The results indicate that the proposed isolation channel retains a highly statistically significant beneficial effect on economic development despite these additional controls. The coefficient on geographical isolation, reflected by the slope of the regression line in Figure 2, implies that, conditional on aerial isolation, the timing of the Neolithic Revolution and factors gauging the productivity of land, as well as controls for institutional quality, disease environment, and continental fixed effects, a 1 week increase in the average time required to travel to a country's capital from all locations in the Old World is associated with a $39 \%$ increase in income per capita in the year $2000 \mathrm{CE}$. In contrast, the effect of these additional channels appear to be non-robust within this sample of countries.

Finally, Columns 6 and 7 augment the analysis with controls for legal origins and the shares of major religions in the population, demonstrating that the

\footnotetext{
${ }^{5}$ The difference in sample sizes between the historical and contemporary analyses arises from restrictions imposed by the more limited availability of data on the additional control variables for institutional quality, fractionalization and disease environment that are used in the income per capita regressions. Indeed, these sample restrictions are imposed throughout the table (even in regressions not employing the additional controls) in order to fairly assess the potential change in magnitude of the coefficient of interest once the additional controls are introduced into the specification. It should be noted that if the sample in Table 1 had been restricted to the 61 countries used in Table 2 , the qualitative results would not be altered.
} 


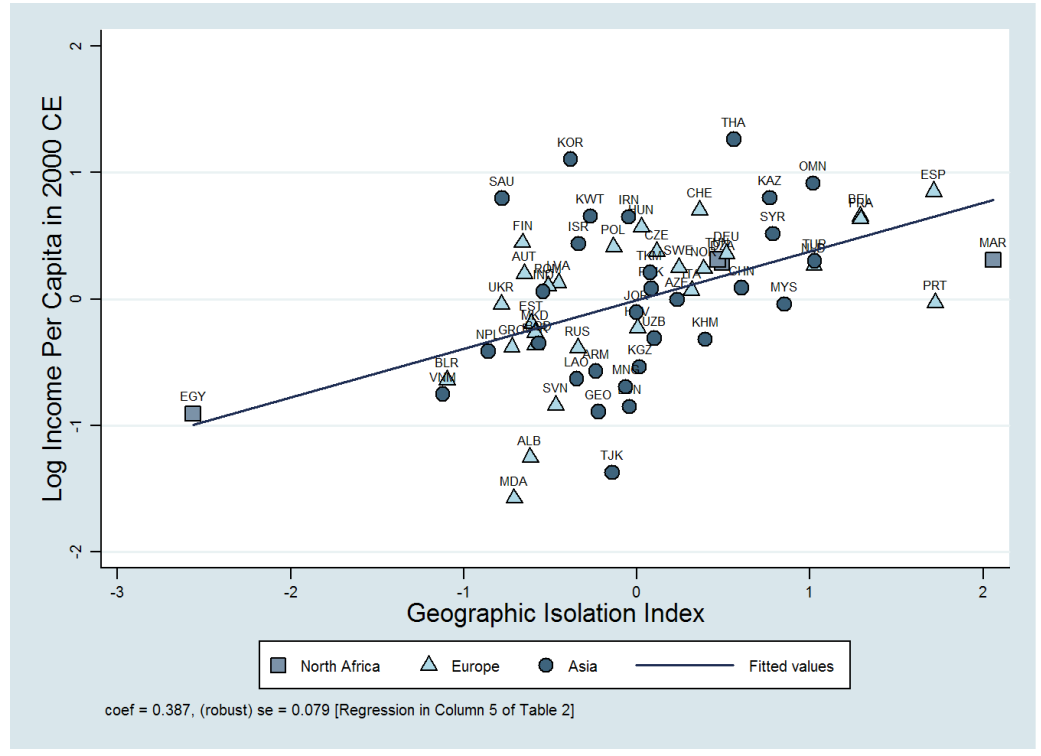

Figure 2: Geographical Isolation and Income Per Capita in $2000 \mathrm{CE}$

Notes - The figure illustrates the partial regression line for the effect of geographical isolation on log income per capita in the year $2000 \mathrm{CE}$, while controlling for the influence of aerial isolation, the timing of the Neolithic Revolution, the arable percentage of land, absolute latitude, land area, constraints on the executive, ethnic fractionalization, malaria risk, proximity to waterways, and continent fixed effects. Thus, the x- and y-axes plot the residuals obtained from regressing isolation and log income per capita, respectively, on the aforementioned set of covariates.

isolation channel remains largely robust under these additional institutional controls that have also been argued to confer historically persistent effects on economic development.

Thus, consistently with the proposed hypothesis, the analysis establishes that, despite its detrimental effect via diminished technological diffusion and trade, isolation in the distant past has indeed generated a persistent beneficial effect on income per capita in the contemporary period.

\section{Concluding Remarks}

This paper establishes that prehistoric geographical isolation has generated a persistent beneficial effect on the course of economic development and contributed to the contemporary variation in economic development across the globe. Contrary to the conventional wisdom, the analysis uncovers a statistically significant and robust positive effect of the degree of isolation in the Old World, prior to the advent of sea-faring and airborne transportation technologies, on contemporary economic development, overshadowing the adverse effects of isolation via diminished technological diffusion and international trade. Preliminary findings suggest that the beneficial effect of prehistoric geographical isolation appears to diminish with the degree of isolation, lending credence to the conjecture that within the context of a larger geographical area, there may be an optimal level of isolation for a given set of country-specific characteristics. 


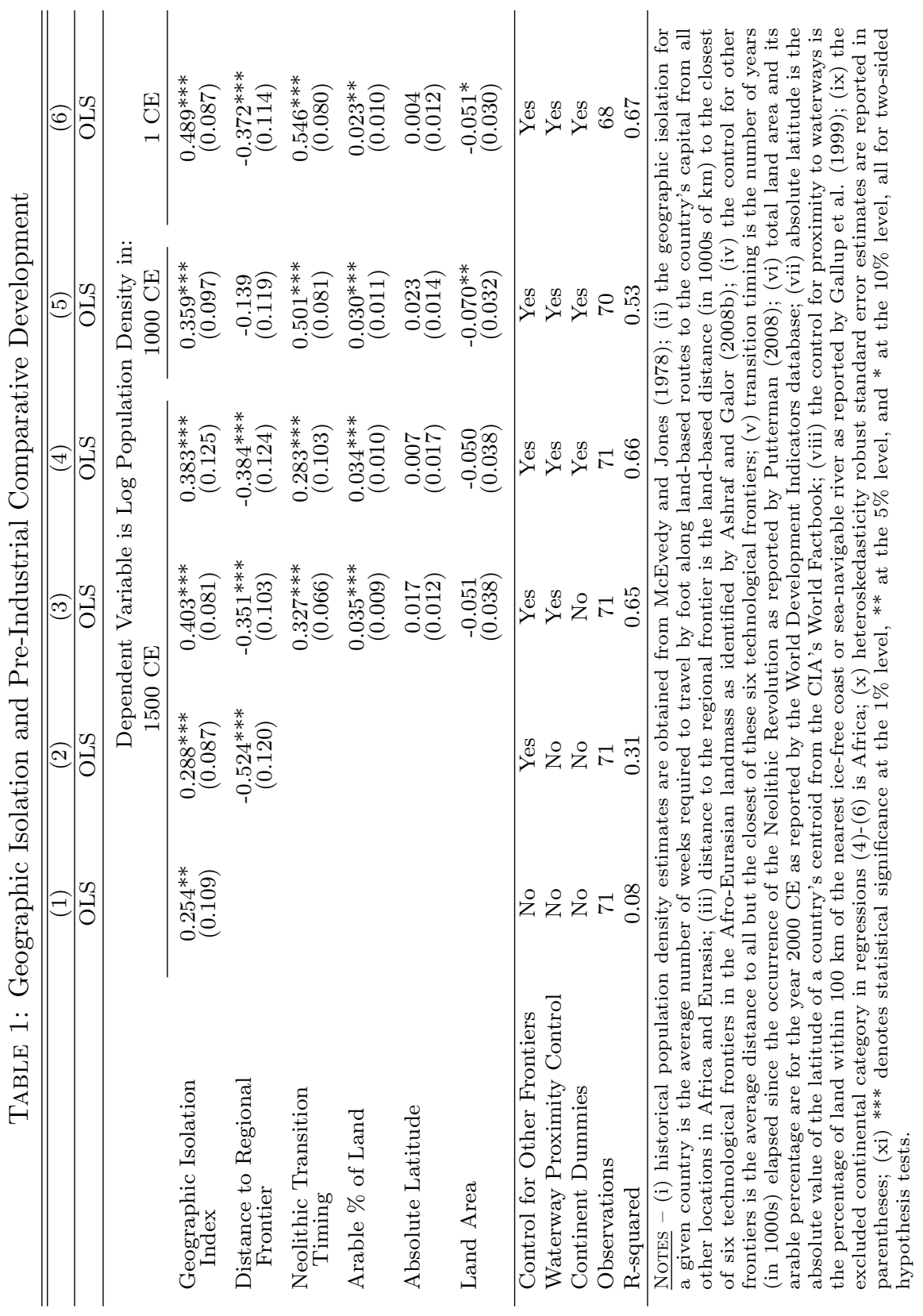




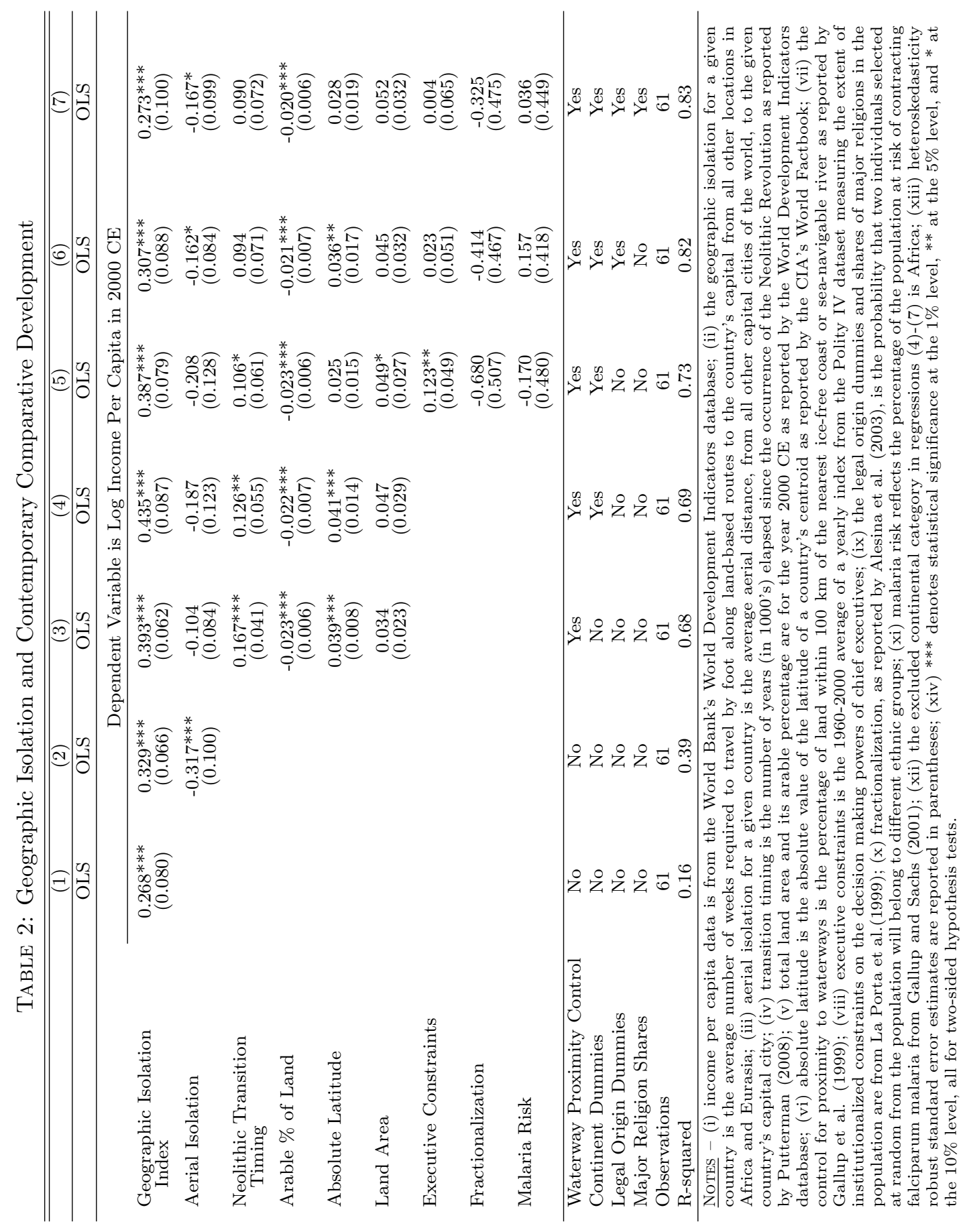


A Data

\begin{tabular}{|c|c|c|c|c|c|}
\hline Code & Country & 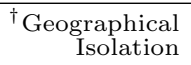 & $\begin{array}{r}{ }^{\ddagger} \text { Distance to } \\
\text { Frontier }\end{array}$ & $\begin{array}{r}\ddagger \text { Aerial } \\
\text { Isolation }\end{array}$ & ${ }^{\S}$ Sample \\
\hline GEO & Georgia & 5.5014 & 1.8320 & 7.4421 & 1 \\
\hline ARM & Armenia & 5.5039 & 1.7768 & 7.3899 & 1 \\
\hline IRN & Iran, Islamic Rep. & 5.6680 & 2.6733 & 7.5994 & 1 \\
\hline IRQ & Iraq & 5.6790 & 2.1215 & 7.2440 & 0 \\
\hline SYR & Syrian Arab Republic & 5.6862 & 1.0292 & 6.9621 & 1 \\
\hline $\mathrm{AZE}$ & Azerbaijan & 5.7219 & 2.4202 & 7.6303 & 1 \\
\hline JOR & Jordan & 5.7295 & 0.8621 & 6.9304 & 1 \\
\hline LBN & Lebanon & 5.7368 & 1.0272 & 6.9448 & 1 \\
\hline TKM & Turkmenistan & 5.7478 & 3.4951 & 8.0112 & 1 \\
\hline ISR & Israel & 5.7584 & 0.7136 & 6.9010 & 1 \\
\hline $\mathrm{KAZ}$ & Kazakhstan & 5.8849 & 3.5160 & 9.1173 & 1 \\
\hline RUS & Russian Federation & 5.9512 & 1.8350 & 7.5896 & 1 \\
\hline EGY & Egypt, Arab Rep. & 5.9651 & 0.0000 & 6.8007 & 1 \\
\hline AFG & Afghanistan & 5.9877 & 3.5174 & 8.5801 & 0 \\
\hline KWT & Kuwait & 5.9913 & 2.6624 & 7.3383 & 1 \\
\hline TJK & Tajikistan & 6.0211 & 3.5602 & 8.6328 & 1 \\
\hline UZB & Uzbekistan & 6.0291 & 3.5989 & 8.7260 & 1 \\
\hline TUR & Turkey & 6.0615 & 0.5231 & 6.9956 & 1 \\
\hline $\mathrm{KGZ}$ & Kyrgyz Republic & 6.0968 & 3.3337 & 9.1065 & 1 \\
\hline PAK & Pakistan & 6.2287 & 3.2967 & 8.8225 & 1 \\
\hline SAU & Saudi Arabia & 6.3723 & 2.6109 & 7.2547 & 1 \\
\hline UKR & Ukraine & 6.4829 & 1.0843 & 7.2241 & 1 \\
\hline NPL & Nepal & 6.5750 & 2.7375 & 9.5882 & 1 \\
\hline BLR & Belarus & 6.6998 & 1.1854 & 7.2679 & 1 \\
\hline IND & India & 6.7042 & 3.3742 & 9.0268 & 1 \\
\hline MDA & Moldova & 6.7210 & 0.7567 & 7.0842 & 1 \\
\hline LTU & Lithuania & 6.8984 & 1.3019 & 7.2545 & 0 \\
\hline MNG & Mongolia & 6.9032 & 0.9427 & 11.6405 & 1 \\
\hline EST & Estonia & 6.9387 & 1.5840 & 7.3961 & 1 \\
\hline FIN & Finland & 6.9495 & 2.1519 & 7.4228 & 1 \\
\hline LVA & Latvia & 7.0040 & 1.4828 & 7.3105 & 1 \\
\hline QAT & Qatar & 7.0126 & 3.5520 & 7.4731 & 0 \\
\hline ROM & Romania & 7.1081 & 0.5357 & 6.9628 & 1 \\
\hline POL & Poland & 7.3405 & 1.3950 & 7.1343 & 1 \\
\hline BGD & Bangladesh & 7.3446 & 3.2033 & 9.9320 & 1 \\
\hline BGR & Bulgaria & 7.4504 & 0.7736 & 6.8804 & 1 \\
\hline $\mathrm{CHN}$ & China & 7.5293 & 0.0000 & 12.2807 & 1 \\
\hline YEM & Yemen, Rep. & 7.6155 & 3.2919 & 7.2046 & 0 \\
\hline YUG & Serbia and Montenegro & 7.6185 & 1.1797 & 6.9109 & 0 \\
\hline HUN & Hungary & 7.6511 & 1.4463 & 6.9798 & 1 \\
\hline MKD & Macedonia, FYR & 7.6659 & 0.9976 & 6.8466 & 1 \\
\hline SWE & Sweden & 7.7564 & 3.0605 & 7.3558 & 1 \\
\hline $\mathrm{CZE}$ & Czech Republic & 7.7617 & 1.0675 & 6.8210 & 1 \\
\hline LBY & Libya & 7.8164 & 2.7715 & 6.7236 & 0 \\
\hline ALB & Albania & 7.8568 & 1.2129 & 6.8249 & 1 \\
\hline $\mathrm{BIH}$ & Bosnia and Herzegovina & 7.8732 & 1.3842 & 6.8809 & 0 \\
\hline AUT & Austria & 7.9035 & 1.6687 & 7.0029 & 1 \\
\hline HRV & Croatia & 8.0421 & 1.6363 & 6.9369 & 1 \\
\hline GRC & Greece & 8.0568 & 1.3128 & 6.7894 & 1 \\
\hline NOR & Norway & 8.1061 & 3.4135 & 7.4283 & 1 \\
\hline PRK & Korea, Dem. Rep. & 8.1326 & 1.1278 & 13.1007 & 0 \\
\hline DEU & Germany & 8.1342 & 1.3966 & 7.1591 & 1 \\
\hline SVN & Slovenia & 8.1780 & 1.4596 & 6.9539 & 1 \\
\hline KOR & Korea, Rep. & 8.3121 & 1.3408 & 13.1908 & 1 \\
\hline VNM & Vietnam & 8.3286 & 3.1018 & 11.1349 & 1 \\
\hline OMN & Oman & 8.5838 & 5.1398 & 7.8392 & 1 \\
\hline TUN & Tunisia & 8.5975 & 2.2059 & 6.8126 & 1 \\
\hline $\mathrm{LAO}$ & Lao PDR & 8.7065 & 3.8668 & 10.8638 & 1 \\
\hline ITA & Italy & 8.8158 & 1.4978 & 6.8736 & 1 \\
\hline MMR & Myanmar & 8.8268 & 4.1238 & 10.3607 & 0 \\
\hline $\mathrm{CHE}$ & Switzerland & 8.8421 & 0.6760 & 7.0862 & 1 \\
\hline NLD & Netherlands & 9.0939 & 0.4362 & 7.3062 & 1 \\
\hline DZA & Algeria & 9.1550 & 1.2543 & 6.9728 & 1 \\
\hline BEL & Belgium & 9.1789 & 0.3108 & 7.2736 & 1 \\
\hline FRA & France & 9.4533 & 0.0000 & 7.2730 & 1 \\
\hline THA & Thailand & 9.5137 & 4.7397 & 10.7152 & 1 \\
\hline KHM & Cambodia & 10.2385 & 5.2028 & 11.0887 & 1 \\
\hline MAR & Morocco & 10.2591 & 0.3085 & 7.2740 & 1 \\
\hline ESP & Spain & 10.3099 & 1.1208 & 7.2669 & 1 \\
\hline PRT & Portugal & 11.0912 & 1.8955 & 7.4617 & 1 \\
\hline MYS & Malaysia & 12.0521 & 7.3146 & 10.9703 & 1 \\
\hline
\end{tabular}

${ }^{\dagger}$ in weeks. ${ }^{\ddagger}$ in thousands of $\mathrm{km} .{ }^{\S} 0=$ historical sample only; $1=$ both historical and contemporary samples. 


\section{References}

Alesina, Alberto, Arnaud Devleeschauwer, William Easterly, Sergio Kurlat, and Romain Wacziarg (2003). "Fractionalization." Journal of Economic Growth, 8(2), 155-194.

Ashraf, Quamrul, and Oded Galor (2008a). "Dynamics and Stagnation in the Malthusian Epoch: Theory and Evidence." Working Paper, Department of Economics, Brown University.

Ashraf, Quamrul, and Oded Galor (2008b). "The 'Out of Africa' Hypothesis, Human Genetic Diversity, and Comparative Economic Development." Working Paper, Department of Economics, Brown University.

Chandler, Tertius (1987). Four Thousand Years of Urban Growth: An Historical Census. The Edwin Mellen Press, Lewiston, NY.

Diamond, Jared (1997). Guns, Germs and Steel: The Fates of Human Societies. W. W. Norton \& Co., New York, NY.

Gallup, John L., and Jeffrey D. Sachs (2001). "The Economic Burden of Malaria." The American Journal of Tropical Medicine and Hygiene, 64(1-2), 85-96.

Gallup, John L., Jeffrey D. Sachs, and Andrew D. Mellinger (1999). "Geography and Economic Development." International Regional Science Review, 22(2), 179232.

Galor, Oded (2010). "The Lawrence Klein Lecture 2008 - Comparative Economic Development: Insights from Unified Growth Theory." International Economic Review. Forthcoming.

Galor, Oded, and Omer Moav (2002). "Natural Selection and the Origin of Economic Growth." Quarterly Journal of Economics, 117(4), 1133-1191.

Galor, Oded, and David N. Weil (2000). "Population, Technology, and Growth: From Malthusian Stagnation to the Demographic Transition and Beyond." American Economic Review, 90(4), 806-828.

Hayes, Theodore R. (1996). "Dismounted Infantry Movement Rate Study." Tech. rep., U.S. Army Research Institute of Environmental Medicine.

La Porta, Rafael, Florencio Lopez-de-Silanes, Andrei Shleifer, and Robert W. Vishny (1999). "The Quality of Government." Journal of Law, Economics, and Organization, 15(1), 222-279.

McEvedy, Colin, and Richard Jones (1978). Atlas of World Population History. Penguin Books Ltd., New York, NY.

Olsson, Ola, and Douglas A. Hibbs, Jr. (2005). "Biogeography and Long-Run Economic Development." European Economic Review, 49(4), 909-938.

Ömer Özak (2009). "The Voyage of Homo-Economicus: An Economic Measure of Distance." Manuscript in preparation, Department of Economics, Brown University. 
Putterman, Louis (2008). "Agriculture, Diffusion, and Development: Ripple Effects of the Neolithic Revolution." Economica, 75(300), 729-748. 